\title{
Prometheus Unbound: The Technology of Bodybuilding in the Nervous Age 1
}

\author{
Nicholas Turse
}

By emphasizing bodybuilding as the technology of physique transfonnation, this article sets out to explore the social meaning of bodybuilding as a response to the crisis of masculinity that occurred during the latter half of the ninetecnth century. Intimately entangled with issues of class, gender, religion, medicine and consumer culture, the history of bodybuilding and the contemporaneous development of a hyper-muscular aesthetic offers a fascinating window through which to view and examine the construction of masculininy.

At the beginning of the twenty-first century, the exceedingly vascular, outrageously muscled physique of the bodybuilder is, if not commonplace or universally embraced, a well-recognized icon of the human form. Over the last ten years, academia has begun to take a great interest in the history and sociology of the art/science/sport of muscular physique enhancement. ${ }^{2}$ Simultaneously, scholars began to reexamine issues of masculinity and the construction of manhood in the nineteenth and twentieth centuries. ${ }^{3}$

Yet, while many have explored either bodybuilding or the social construction of masculinity, few scholars have made serious efforts to comprehensively examine the interrelated nature of these two subjects. This article seeks to bridge that gap by exploring the larger social meaning of the history of bodybuilding through an examination of the crisis of masculinity that occurred during the latter half of the nineteenth century and the contemporaneous development

I I an indebted to Dr. I jsa Hersctibach for her contunems and criticisms of this anticte, prepared wtile I was a Master of Arts candidate in the History of Technology. Hinvironment and Medicine a Rutgers University. Newark/New leney Institule of Tectnology. I alo wish to thank Past Impreffert's anonymous reviewers for their heipful suggestions and insights

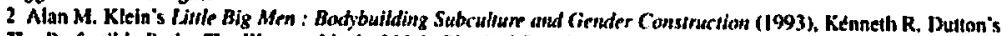
The Perfectible Body: The Ilestem Ideal of Male Physical Drurlopmesu (1995). Micturel A. Buad's The Seulpisure Machine: Physical Culture and Body Polinirs in the Age of Eupire (1997). Leslie Heywow's Bahmaken: A

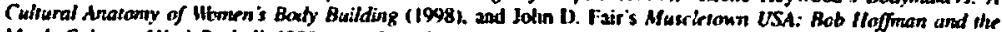
Santy Culiure of York Barbell (1999) are a few of the texts that have emerged from the effort to seriously understand bodybuilding and its stheullure.

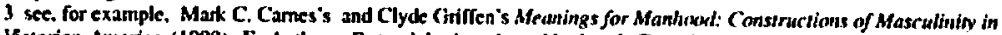
Iictorian America (1990). E. Anthony Rotundo's Amterican Manhood: Tranuformations in Masruliniry from the Reuplution to the Modem Era (1993). and Gail Bederman's and Catharine R. Stimpson's Mfanliarss of Civilizatian: A Culurel Histery of Gonder and Race in the Uinied Svates. 1890.1917 (1996). 
of a hyper-muscular aesthetic. Intimately entangled with issues of class, gender, religion, medicine and consumer culture, the history of bodybuilding offers a fascinating window through which to view and examine the construction of masculinity, both past and present. By emphasizing bodybuilding as the technology of physique transformation, the author hopes to open new avenues of exploration for historians of technology, public health and medicine to reexamine the construction of the human form.

\section{Nervous Men in a Nervous Age}

In 1869 America was in a state of flux. A nation that, in the words of Oliver Wendell Holmes, had been "touched with fire" during the civil war, found itself in the throws of the Second Industrial Revolution. This move into modernity brought unprecedented social and cultural conditions as well as a new malady: neurasthenia, or "nervousness," which rapidly became the preeminent medical disorder of an entire generation.

While he did not invent the term, New York neurologist George M. Beard was the first physician both to describe neurasthenia as a clinical entity and to treat the disease with stringent scientific inquiry. ${ }^{4}$ Beard's highly influential papers and texts, "Neurasthenia, or Nervous Exhaustion," (1869), A Practical Treatise on Nervous Exhaustion (Neurasthenia): Its Symptoms, Nature, and Sequences (1880), and his famous American Nervousness: Its Causes and Consequences (1881), had a profound impact upon the American populace. According to Beard, neurasthenia was "modern and originally American; and no age, no country, and no form of civilization... possessed such maladies [before]."5 The increased pace of everyday life, the new emphasis on "brainwork," the competitive Protestant work ethic, urbanization, and unprecedented technological leaps provided the exact environment necessary for its occurrence and spread.

4 F. G Gosling. Befor' Freud: Neurasthenia and the American Medical Communiry, 1870-1910 (Chicago Universily of Ilinois Press, 1987 , p. 26f.

5 George M. Beard, American Nenousness: Is Causes and Consequences (New York: Amo Press, 1972 [1881]). Pp. vii.viii. 
The syndrome that Beard described was a disorder whose diverse symptoms filled two pages of text. Neurasthenia became the pre-Freudian catchall for "practically every emotional disorder short of insanity...." $A$ variety of cures were set forward by which the disease might be overcome. For women, bed rest was generally recommended because it was felt that over-activity, due to presumed female frailty and hypersensilivity, caused the disorder. While some men were also prescribed "the rest cure," most male neurasthenics were directed to fresh air and exercise. Weight-lifting, mountainclimbing, hiking, hunting, organized sports, horseback riding, Western excursions and manual-labour were typically prescribed to refit men for the modem world where the "fittest" ruled. It was thought that these activities would foster survival instincts, primitivism, competition, aggression, and muscle-building. Renewed and reinvigorated by such activities, the neurasthenic could return to the civilized world that had temporarily debilitated him. ${ }^{7}$

"Muscular Christianity." a catch phrase that was as much a part of the late nineteenth century as "American nervousness," linked morality and physical culture in a similar effort to combat the perceived "crisis of masculinity." As bodybuilding historian David Chapman writes: "the doctrine sought to reconcile physical vigor with spiritual sanctity" and in this way to reassert manly religiosity." Just as neurasthenia was perceived to have feminized men, the organized church was seen to have weakening masculinity. Women had for some time been taking a more active role in religious organizations and were considered as having a deleterious, feminizing effect on religious institutions. Many began to complain that the church itself, by exhorting Christians to be meek, humble and accepting, had an emasculating effect, lurning men into what professional baseball player turned preacher, Billy Sunday, called "off-handed, flabby-cheeked, brittle-boned, weak-kneed, thin

6 Costirg. p. 9.

7 Lutz. pp. $31-32$

8 David Chapman, Sandow the Magnificen: Eugen Srtondow and the Begirenings of Bodybuilding (Urbana:

University of Iltincis Pressl. p. 112. 
skinned, pliable, plastic, spineless, effeminate, ossified three-karat Christian[s]."9 Muscular Christianity was one response to these charges, replacing the clasped hands of prayer with clenched fists and dumbells, the Bible with exercise manuals and religious hymns with the counting of repetitions. Jesus had died on the cross, but a new man would be resurrected: a Messiah with bulging biceps who would toss aside the stone laid across the face of his tomb and emerge a muscular "king of kings."

\section{The Technology of Bodybuilding}

While waiting for the Messiah to appear, the muscular Christian needed to prepare himself to do battle with both Satan and his own nervous body. Ironically, neurasthenia, a disense brought on by modernity, was seen to require technology as its antidote: namely the technology of bodybuilding. While not generally recognized as a technological innovation, bodybuilding is a "body technology" by virtue of the fact that it is a systematized technique for restructuring and reconfiguring the human form by utilizing specific tasks, drills and forms of training (e.g. weightlifting) and various apparatuses (e.g. weights and pulley machines). Further, it is essential to recognize bodybuilding as just one of many physique transformation technologies developed at the fin de seicle, which included, for example, modern cosmetic surgery procedures such as intranasal rhinoplasty (1887) and rhytidectomy (facelift) (1901), the employment of synthetic coal tar hair colorants (1890s), commercial cosmetics (1890s), biomedicallyprincipled dieting (1880s-1890s), methods of organotherapy, such as thyroid grafting (1890s) and the pharmacological use of thyroid extract to treat obesity (1893), and French physiologist Charles Edouard Brown-Séquard's utilization of injected animal testicular material (1889), which prefigured the future bodybuilding technology of anabolic steroids. ${ }^{10}$

9 Billy Sunday, Sembon transcript, New York Cily, 8 April 1917 (evening), p. 3, Sunday Hapers (Inicmofilen reel

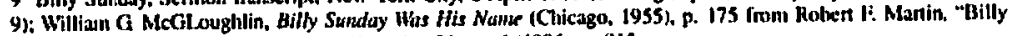
Surday and Christian Manliness," The Ilistorian 58, no. 4 (1996). p. 815. 
While bodybuilding (as we now know it) is a relatively recent phenomena, the practice of building the human body has a long past, stretching from the ancient Greeks, who idolized the muscular definition and proportion of the athlete, to the Renaissance, where the muscular male emerged from the Dark Ages to take his place on the ceiling of the Sistine Chapel, the brawny male has been a recognizable cultural figure. For the Greek athlete, the Roman centurion, and even later, the chivalric knight, a well-muscled body was something to strive for and to admire, however, there was always a greater emphasis on function over form. A muscular physique provided these men with speed and power for athletic pursuits, work and war. Muscle meant the difference between victory or defeat, and life or death. Psychological benefits were a by-product and not the primary goal of exercise.

By contrast, the technology of bodybuilding that developed during the nineteenth century placed less emphasis on function than form. As bodybuilding scholar Sam Fussell astutely observes, "[b]y making a labor of leisure, a vocation of recreation, bodybuilders lampoon wage slaves and nine-to-fivers. [The bodybuilder] is a perversion of puritanism and utilitarianism. He doesn't use his muscles to build bridges, but to raise eyebrows." 1

Fussell describes perfectly the reasons behind the development of bodybuilding in the age of nervousness. Wracked by neurasthenia, alienated from his physical self by "brain work," the "nervous" male sought rebirth, much like the Puritan. However, while the Puritan eschewed the sinfulness of the flesh, the would-be bodybuilder reveled in it. As a pencil-pushing brain worker, his need

10 Nieholas Turse, "Prometheus Boutnd: The Techntrilogy of Bodybuilating in the Nerious Age," (MA thesis. Rutgers Universily. Newart/New Jersey Institute of Technology. 1999). Nelly Gucksoom. Beyond the Nasural Bach: An Arheology of Sex Homsones (New York: Routkdge. 1944). pp. 18-19. Eilizabeth Haiken, tirnus Eny: A Ilistory of Cosmetic Surgery (Bahinmor: Johns Hoplins Press, 1997) p. 20. Ivan Mt. Tuppin The Alodem Rhytidectomy." Clinics in Plastic Surgen 19. No. 2 (April 19921. p. 383. Sander Gilman. "Creating Beaudy to Cure the Soul: Race and Psychology in the Shaping of Aesthetic Surgery." (Duitam: Duhe Universily I'ress. 1998). 22. "Myxoedenta Treated By Thyroid-grafting", Mrdical Progmess (3 January 189|), p. 19. "The Elixir of Youlh." The Medicnl Recond (20 July 1889), p. 69.

II Sam Fussell. "Bodybuilder Americanus." The Make Body: A Special Issue, Michigon Quarserly Reviow 32 No.

4. Fall 1993. p. 579 . 
for highly developed muscles was, physiologically speaking, unneeded excess. His muscles, like the age's gilt veneers, were showy extravagances of a rapidly developing consumer culture. A "civilization" which, writes historian George Mosse, was "ever more visually centered... when attitudes toward society and the nation were often expressed in aesthetic terms."12

To understand the growth of the technology of bodybuilding during the late nineteenth century, it is helpful to examine the endeavor through the lens of Thorstein Veblen. Through Veblen's analysis of turn-of-the-century socioeconomics, one is able to better understand, not only the age itself, but also a key impetus behind bodybuilding and its development within this era. Veblen pioneered a school of thought which criticized wasteful spending or "conspicuous consumption." In his seminal text, Theory of the Leisure Class (1899), Veblen criticized the wealthy for spending capital on useless status symbols instead of conserving through reinvestment. Veblen argued that wastefulness halted social evolution and stifled the improvement of socio-economic conditions. His economic analysis mirrored the medical diagnosis of George Beard who saw in "nervous bankruptcy" increasing numbers of Americans wasting their "nerve force" through work or sexual excess.

The technology of bodybuilding emerged during this era as a form of "conspicuous consumption." While the blue-collar worker built muscle in productive labor, the brain-worker lifted weights for no purpose, save aesthetics. While some might argue that even brainworkers were improving their overall health and productivity, such benefits were merely a by-product of bodybuilding which in itself focused on training for appearance. The manufactured or "built" body was an unnecessary commodity to be acquired and "conspicuously consumed." Unlike the "natural" un-built physique,

12 Creorge Mosse. Nationslism and Sexuality: Afuldle.Class Moralioy and Sexwal Noms in Modem Europe (Madison: University of Wisconsin Press, 1985), p. 10 quotcd in Michacl A. Budd, "Heroic Ilodies: Physical Culture Comunence and the Proatice of the Perfected Self, 1898-1918," Ih,D. dis. Rutgers. The State Universily of New Jersey. 1992. p. 55. 
it was neither primal nor pre-cultural. It was a manufactured, modern product; an extravagance whose value, while not monetary nor immediately quantifiable in pecuniary terms, fit Veblen's model of consumption. ${ }^{13}$

Veblen's assessment of leisure can also be usefully applied to the technology of bodybuilding. While few would classify hefting weights as leisurely, bodybuilding fits the definition of leisure as a "non-productive consumption of time." Thus the built body, the muscular trophy, becomes a signifier of "the unworthiness of productive work." Showy muscles are "evidence of pecuniary ability to afford a life of idleness," or, if not idleness per se, the ability to devote time to economically non-productive acts. Veblen's observation, that the "cultivation of the aesthetic faculty requires time and application, and the demands made upon the gentleman in this direction therefore tend to change his life of leisure into a more or less arduous application to the business of leaming how to live a life of ostensible leisure in a becoming way" seems a tailor-made description of the bodybuilder who devotes time, energy, and capital in a "wasteful" pastime. 14 Bodybuilding is the means by which its practitioner puts "in evidence the leisure that is not spent in the sight of spectators." This evidence is, then, the muscular body-built in private-but showcased in public. ${ }^{15}$

Veblen's theories can also be read as an indictment of bodybuilding as the pursuit of vanity when he writes that:

considered simply in their juxtaposition with the human form, the high gloss of a gentleman's hat or of a patent-leather shoe has no more intrinsic beauty than a similarly high gloss on a threadbare sleeve; and yet there is no question but that all people (in the Occidental civilized communities) instinctively and unaffectedly cleave to the one as a phenomena of great beauty and eschew the other as offensive....16

13 The "un-buift phystique." is not necessarily un-muscular, only not thanufactured for aesthelic reasons.

if Veblen, Lrisure Class in Lemer. Porrable Ubblen. p. 117 . Vebten defines waste as an "expendinue which does not serve human life or human well-being on tie uthate..." Ibid., p. 137.

15 Ibid. p. 90.

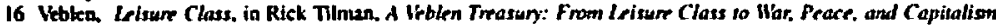
(Amonk, NY: M. F. Shape, 1993), p. 72. 
While the functional value of brain-workers building "excess" muscle was limited, the conspicuously consumptive act of muscle building did provide psychological currency. In a world with a rapidly accelerating pace, where individuals were able to see more (people, places and objects) than ever before, the need to differentiate oneself became increasingly important. According to Veblen, as "the population increases in density, and as human relations grow more complex and numerous, all the details of life undergo a process of elaboration and selection; and in this process of elaboration the use of trophies develops into a system of rank, titles, degrees and insignia." For the modern office worker, already possessed of social rank, educational certification and a business suit, muscles became a means of differentiation, denoting one's status at the pinnacle of one's class: a modern brain-worker, with sufficient leisure to develop "primitive" muscles with which to stave off nervousness.

In the late nineteenth century, men were increasingly leaving the small towns, where one was conspicuous precisely because there were few individuals, and moving into cities with tens of thousands of inhabitants. For a man to make an impression amidst the urban masses, he would have to be striking. In a culture of debilitated office workers, one could proclaim immunity to effeminacy, and be noticed for it, by building a hyper-masculine shell of muscularity. As the German psychologist Hermann Lotze observed, "Clothing, by adding to the apparent size of the body... gives us an increased sense of power, a sense of our bodily self-ultimately enabling us to fill more space." 17 Body-building offered all this and more, providing a realistic appearance of power and a semi-concealed "weapon" in his own muscles. Modern bodybuilding author Sam Fussell speaks to this point when he writes of having been frightened of his vulnerability in the "big city" and turning to bodybuilding to provide "great chunks of tanned, taut muscle, [a] modern day armor[.] A

17 Herman Lotze. Microcrogrus. 1856-1864. quoted by lilugel. Psychology of Closhes. pp. 592-595. quoted in Steven

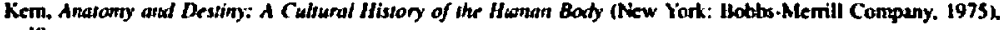
p. 19. 
human fortress- a perfect defense to keep the enemy host at bay." Fussell then queries, "What fool would dare storm those foundations?"18

\section{Sandow: Koenig of Bodybuilding}

Nineteenth century Muscular Christians waited, Indian clubs and dumbbells in hand, for a new Messiah, a "king of kings" who would transform them from enfeebled weaklings to supermen of masculinity. The new Messiah was a necessity for, like the feminized religion the muscular Christians railed against, Jesus too had become "soft and effeminate." As the American advertising executive and author Bruce Barton would later object in his best-selling book The Man Nobody Knows (1925), "Jesus was the 'Lamb of God.' ... It sounded like Mary's little lamb, something for girls-sissified." Barton also criticized popular depictions of Jesus, complaining that "[a]lmost all the painters have misled us. They have shown us a frail man, undermuscled, with a soft face-a woman's face covered with a beard." 19 Century Magazine had expressed similar concerns as early as 1896, when it called for "vigorous, robust, muscular Christianity... which shows the character and manliness of Christ." In an age in which "all" men (provided they were white, Protestants of middle-class or above social rank) could aspire to be supermen, a new iconic figure was needed; a figure $\mathrm{E}$. Anthony Rotundo termed "[a] hardy Jesus with rippling muscles." 20

Only two years before George Beard proclaimed the "age of nervousness," the man who would later come to symbolize these attributes of masculine strength was born. Delivered into a world wracked by neurasthenia, Friedrich Wilhelm Muller seemed, at first, unexceptional. As he later wrote, "As a child I was exceedingly delicate. More than once, indeed, my life was despaired of. Until my tenth year I scarcely knew what strength was." He was, however, to

18 Sarmuel liussell. Muscle: Confrssions of an Unfiteby Bonbbuilder (New York: Poscidon Press, 1991), p. 24. 19 Bruce Barton. The Afun Noborty Knows (Intianapolis. 1925). pp. 11.13, 38 qunted in Manty Nesselbush Gireen. "Ciender Imsges in Consenvative Protestantism. 1900-1940," The Historian 58, mo. 3 (1996). p. 546.

30 Rotunda, p. 224. 
learn "what strength was" and, as Eugen Sandow, would become the grentest physical culturist the world had ever seen. ${ }^{21}$

Whether or not Muller had been the scrawny, sickly youth he purported to have been or whether it made a better tale once he became the iconic strength symbol of his generation, Eugen Sandow masterfully played upon the fears of his age. Both men and boys could empathize with the young Muller. Weak and debilitated, their man/boyhood "despaired of," they sought to find a cure from "the strongest man in the world."

Sandow stood out in age of vaudeville showmen as the first example of what we now recognize as the body-builder. He was not the strongest man in the world, despite the fact that he billed himself as such. 22 Instead, he became one of the most recognizable men of his age, 23 not by breaking coins, tearing packs of playing cards and lifting weights (all of which he did), but because he looked the part. He was the epitome of what Bram Dijkstra has termed "the blond god" ideal of nineteenth century manhood. ${ }^{24}$ Finely proportioned, well-defined, and muscular, he looked like a living piece of classical sculpture. The New York Herald in 1893, called "Eugene [sic] Sandow [a] modern marvel of physical power, beside whom the average man is puny...." The New York World echoed these sentiments, stating that Sandow is "beyond question, so far as is known and so far as record goes, the nearest to physical perfection of any man." Further, The World captured the true essence of bodybuilding when it wrote, "Sandow's actual feats of strength, however, do not make up his strongest claim to attention and veneration. The great point is that man who does all of these things... does them because he has developed to the highest point every

\footnotetext{
21 Hugen Sandow, Sinength and How to Obiain / (l andon: (iate and Polden, 1897). p. 8y.

22 Bodybuilding autror Kenneth Durton cuncurs with my assessment calling Sandow the " founder of hodybuilding (Dulton. p. 105)."

23 In Fü for America. p. 213 Hancy Green states thal "By 1890 [Sandow] and the boxer John L. Sullivan and wrestles William Muldoon and Ciecrge Ilackenschunidt uere probably the nost fanceus athletes in the United Stries." I would not argue that at some point in time this was true, bud I would put the due later than I890. as Sandow's lirst verifiable visit the United Siates was not until June 1893 and he was not a well-known figure upon arrival.

24 Bran Dijksira, dols of Penversiry: Fantasies of the Feninine in the Fin-de-slecte Culturr (New Yoth: Oxford Universily Press, 1986), p.200 in Kon Straton, The Desirable Body: Cuhurnl Fetishim and the Enutic of Consumption (New York: Manctuster Univensily Press, 1996), p. 119.
} 
separate muscle in his body."25 After Sandow, the appearance of strength began to be perceived as more important than strength itself. Bodybuilding had been born. Once a secondary event "tacked on" to weightlifting events or positioned at "the back [end] of strongman shows," bodybuilding became the main draw to "bring in people." 26

Audiences flocked to see Sandow's musculature, seeing there the embodiment of masculinity or even a hyper-masculinity, especially when compared to the slight and scrawny physique normal in the men of the nervous generation. An 1877 study of the stature of volunteers during the American Civil War showed the average height of the American male to be 67.4 inches with an average weight of 141.96 pounds. In 1917, statistics showed the first million World War one "doughboys" drafted were roughly the same height (67.5 inches tall) but had actually lost weight, dropping to a meager 141.5 pounds. ${ }^{27}$ In contrast, Sandow was a model of physical fitness. Twenty-nine years of age at the turn of the century, he stood 69.25 inches at the weight of 202 pounds. An inch and three quarters taller and a full sixty pounds heavier than the "average" man, while maintaining (presumably) lower body fat, Sandow truly fit the bill of a muscular messiah. He was what, in terms of physicality, what Nietzsche and Duhring, had called for: a super-man.

\section{Prescriptions for Bodyburlding; Medicine, Masculinity, and Modernity}

Sandow's impact, however, transcended the image of a built body. Historian Michael Budd notes that Sandow's mind was also valued: "at the time one might have easily placed the ideas of Sandow, Freud and Havelock Ellis on more or less equal footing." Budd attributes this to the preponderance of "new physiological and psychological theories and methods [that] were just developing," and which, due to progressive faith in science and biomedicine, "possessed important political dimensions that would be absent

25 Herald and Hbrk quored in Alercer Adem. Sandow On Mhysical Training. (New York: J. Selwin Txit and Sonk 1894), pp. 115, 114, 108.

26 Greg Pacek. "Thie ISig Muscle Behind Modybulkding." (Pan Nwo), Ciby Sions 12). Noventurer 1981. p. 37 from Klein. p. 97.

27 Chapmar. p. 125. 
today."

In the nineteenth century, when the medical profession was striving for cultural authority, there existed a number of "alternative" medical practices such as homeopathy, botanical medicine and osteopathy. One of these alternatives was bodybuilding. As a curative for neurasthenia and a myriad of other diseases, the art/science/practice of building one's body was embraced by many in the scientific and medical communities. Sandow demonstrated this in his work, The Power of Evidence, in which testimonials to the "Sandow system" were given by blood pressure diagnostics pioneer, Sir Lauder Brunton and nearly two hundred prominent members of the medical community. ${ }^{28}$

Independent of the legitimacy which professional medicine extended to bodybuilding, physical culture was presented to the middle-class as a quasi-academic pursuit. In accordance with the scholasticism that surrounded bodybuilding, numerous "professors" of physical culture, so-called not due to advanced degrees but out of respect for hands-on knowledge or the appearance thereof, were a staple of the "body technology." This, coupled with an increased interest in college athletics and the growth of academically affiliated gymnasiums beginning with the University of Virginia in 1853 (Harvard, Yale, Amherst and later Princeton followed suit), endowed physical pursuits with the aura of cultural respectability. ${ }^{29}$

That year, 1853, also marked the arrival of George Winship to Harvard. The smallest member of his class, Winship fit the stereotype of the scrawny weakling. Humiliated by a campus bully, Winship turned to the gymnasium where, through heavy resistance training, he built himself into a "Roxbury Hercules." At 5'7" and 143 pounds (roughly the size of the average Civil War volunteer), Winship possessed strength "twice that of an ordinary man" and the ability to lift "four hundred and twenty pounds [in the style of a

28 Budd, Heroic Bodies," pp. 240. 240 in.

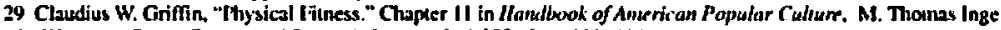
ed. (Wextpon. Conn: Girenwood Press. 1981). pp. 266-277. Hy 1909 . 114 colleges posiessed go manasiums and III Thad some wert of physical colucation departneat." 
partial deadlift]." Graduating with his M.D. in 1857, Winship attracted a huge following by writing articles for popular publications and active participation on the lecture circuit. He would go on to open a large gymnasium in Boston where he practiced medicine, taught physical culture and sold strength-building paraphernalia. ${ }^{30}$

Described by bodybuilding author Alan Klein as "the earliest and most successful protagonist of bodybuilding," Winship advocated the use of heavy weights, as opposed to lightweight theorists such as Dioclesian Lewis, in order to re-mold one's physique. Aimed exclusively at men (presumably the female "constitution" could not handle large weights), Winship brought legitimacy to bodybuilding through his medical degree and affiliation with higher learning. ${ }^{31}$

The Harvard connection to bodybuilding was continued by a man closely tied to Winship. Dr. Dudley A. Sargent. After serving as the director of the Bowdoin College gymnasium and obtaining his medical degree from Yale University, Sargent founded his own "Hygienic Institute and School of Physical Culture" in New York City. In 1879 he was hired as Harvard's first professor of physical training and director of the newly built Hemmenway Gymnasium. ${ }^{32}$ Troubled by the "generation of college students who tended to debility from too much "brain work," Sargent advocated weightlifting as a method of "ensur[ing] the equal and symmetrically balanced development of the body." Having personally trained such notables as the on againoff again neurasthenics Theodore Roosevelt, Henry Cabot Lodge, Francis A. Walker, and Augustus Hemmenway, Sargent was acknowledged as the "dean of American physical educators from the 1880s until his retirement in 1919." His methods were highly respected in all circles. ${ }^{33}$

When Sargent arrived at Harvard he found, as was commonly the case, that only athletes were using the gymnasium. Sargent lamented that "of the whole number of students not more than ten per

30 Gieen, Pp. 199, 201. Toudd from Pear, sp. 418-19, Klein. p. 34.

31 Klein, pp. 34-35. Green. p. 202.

32 Green, p. 202 Grillin. p. 267.

33 Green, p. 214. Klein. p. 35. Mrotek, p. 19. Gireen. p. 204. Mroyek, p. 36. 
cent [sic] give any attention whatever to physical exercise and that less than six per cent [sic] lake it systematically as a means of culture and development." Sargent began to focus his efforts on the neurasthenic student body, at large, charging, "let us give... more attention to the instruction of the weak." To this end, Sargent developed a bodybuilding system focused on "individualized exercise programs." Sargent's system of bodybuilding shunned light gymnastic equipment and Indian clubs, opting instead for pulley machines. An early (probably the first) advocate of what is today known as circuit training, he designed more than eighty machines, from high pulley and chest expansion devices to finger and leg exercisers, to systematically correct any physical inadequacy.

Sargent's method began with a questionnaire and a comprehensive physical examination, followed by his "trademark" battery of tests designed to measure strength and muscular endurance, and concluded with the precise anthropometric measurement of each subject's body parts. The heart and lungs were examined and notes were made concerning the skin, spine and "any other point which the tape measure failed to indicate." Sargent's use of anthropometry drew upon a large body of existing scholarship. Utilizing various bodily measurements, anatomists and ethnologists had endeavored to create a system of racial, ethnic and sexual classifications. While Sargent was neither the first nor the only practitioner of the science of somatotypes, he was one of the most rigorous in his analytical methods and prodigious in his number of subjects.

Based upon the information rendered by his subjects, Sargent wrote precise prescriptions on note cards for exercise, diet, sleep, bathing and even clothing for his clientele. He combined, in effect, the tasks of a modern day personal trainer and image consultant. These prescriptions were tailored for every individual and Sargent prided himself on the fact that on "none of the cards were printed formulae." After six months the subject would revisit Sargent to be remeasured and photographed. Sargent's use of the before and after photograph reveals the visual bias endemic to bodybuilding. 
Sargent's diagnoses, prescriptions and tests evidence the interplay of science and medicine in the physical culture of the era. His systematic application of technology purported to yield a true "exercise science." Utilizing dynamometers, a manometer, a spirometer, along with parallel and horizontal bars, Sargent developed a mathematical method of measuring muscular strength. After 1890 , all Harvard athletes were required to have the strength of their back, legs, forearms, biceps, triceps, pectorals and lung capacity tested by Sargent's methods in order to qualify for their particular sporting endeavor.

In addition to testing and measuring his students, Sargent also, by arrangement of the [New York] World, traveled to New York to make a "thorough anatomical test" of Eugen Sandow. Completed in a Broadway hotel, Sargent put the bodybuilder through a series of examinations to ascertain Sandow's physical capabilities. The World commented that Sargent utilized:

[i]nstruments to blow in to determine your force of expiration; a machine to find out how many pounds you can lift, another to see how hard you can squeeze, another to register the power of the muscles of the chest, another to measure the exact amount of air you can take into your lungs... [t]here was also an electrical apparatus which was so contrived that it recorded on a cylinder, covered with a thin conting of lampblack etchings showing how regularly you breathe, and the relative proportion of breathing done by the abdomen to that done by the chest... [and t]here were also a set of scales....

Utilizing the measurements that he took of Sandow, Sargent created an "anthropometric chart" of the bodybuilder, just as he had for students at Harvard. The chart "show[ed] the relation of the individual in size, strength, symmetry and development to the normal standard." Sargent's chart utilized over fifty statistics from age, weight and height, to waist, chest depth, and lung capacity, plotted along a line 
graph. When interpreting his graphs, Sargent could compare the subject's measurements with averages representing the bodies of "various segments of the American community" created using "purely scientific measurements." 35

By plotting a graph containing all the subject's measurements, Sargent was able to reduce his subject to a single streak of ink and tell, at a glance, how physically "normal" the subject actually was. Sargent's classification of normalcy was gauged by the average measurements for a particular population group; e.g. "young white males." Once a person's data was plotted, his/her normalcy was determined by how closely his/her line stayed to the fiftieth percentile. ${ }^{36}$

While Sargent searched for individuals with perfect symmetry, he generally found himself with charts that zigzagged. Over the course of his career, he accumulated over 50,000 anthropometric measurements, however Sargent was hard-pressed to find, "[t]he straight line [which was] the physical sign of health and longevity, of perfect structure and harmony of function, a symmetrical development of the whole body." ${ }^{37}$ Having been unsuccessful in finding perfectly symmetrical humans, Sargent "built" bodies, in the form of statues, of the fifticth percentile man and woman that, like Sandow himself, were put on display at the 1893 Colombian Exposition. ${ }^{38}$

In reading Sandow's anthropometric chart, Sargent ascertained that the bodybuilder matched his athlete models in many ways, having the "ideal" weight, height, length of foot, and girth of ankles. Sandow, however, failed to match in other categories, as his muscles were "conspicuously larger than those of the model." Sargent's scientific analysis of Sandow offers intriguing insights into medical science and its relationship to the technology of bodybuilding. Sargent's language blends scientific assessment, anthropometric terminology, and personal opinion. Medical assessments of muscle fibers ("unusually small, but ... more 35 Gertxr. p. 290. Adam p. 123.

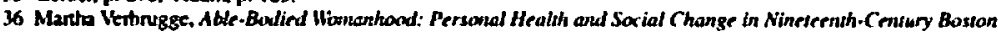
(New York: Oxfond Universily Press, 1988). pp. 132-135.

37 Dudley Sargent. "The Physical Proportions of the Tyjical Man." Scribmer's Magatine 2 (July. 1887), 16, quoted in Vertrugge. p. 135.

38 Hachensmith. p. 365 . 
numerous than in the average athlete") are interspersed with less scientific observations, such as, "I have found it as a rule that strong, large men are... inclined to be dull and stupid."3\% In Sandow, however, Sargent found a strong man with knowledge of anatomy and physiology, able to "call the muscles by their proper names." Sargent stated that he "would be glad to have [Sandow] come and lecture before the students of Harvard."

In 1902, Sandow took Sargent up on his offer during a visit to Boston. Sargent used "the opportunity to deliver a lecture on Sandow and his fine physique," in the then-new Harvard Union. Sargent would write in the New York Herald, Sandow "is particularly valuable... to the young men of America. [His] visit to the [U]niversity will stimulate great interest among the students. The fact that is impressed upon them is that what he has been able to do others may do." Sargent concluded with the flowery praise of stating, "Sandow is the most perfectly developed man the world has ever seen." Such high praise from a doctor and leading academic of a "mere" bodybuilder attests to the legitimization and medicalization of bodybuilding in the age of nervousness.

Sandow's contact with academin was not limited to Harvard. Professor Ray Lankester of the natural history branch of the British Museum also found Sandow's physique to be flawless. In 1901, Sandow was asked by Lankester to represent the "Caucasian Race" in the British Museum's "major races of the world" exhibit. Sandow was, through a grueling process over a number of days, covered plaster so that a complete body cast could be made. While the process of casting Sandow's fully tensed musculature obscured his physique in the completed statue, the fact that Sandow's body was thought to be the finest example of Caucasian man, speaks volumes for the scientific opinion of his built body. ${ }^{41}$

39 Adam. pp. 120. 121. One wonders utral Itavand's "large, strong" men feit ahoul the statemeal of their gymuasium director after reading this quote.

40 Ellen Gerter. Innowators and Institutions in Physical Educasion (ITtiladelphia: I ca and Iebiger, 1971), pp. 283. 291. Chapman, pp. 122, 138.139.

41 Chapman. pp. 119-122. Sandow sent the only copy of his statue to Dhadley Sargent. The copy is currently inissing from Harvard and presumed kad. The origial is located in the basenent of the British Mluscum. 
Attesting to the scientific opinion of Sandow's physique, the [Glasgow] Evening News reported that "[t]he amount of interest aroused [by the bodybuilder's frame] in medical... circles has extended all over the world..." In the December 24, 1892 issue of The Lancet, a lecture by Surgeon-Major Deane given in connection with an exhibition by Sandow before Army cadets at the Royal Military Academy, in Woolrich, England was chronicled in detail. After speaking in Beardian terms of depletion ("nature had given us a capital reserve... [which] was continually being drawn upon"), Deane used Sandow to illustrate the product of the technology of bodybuilding.

Sandow's military exhibition, like his stage act, relied upon musculature far more than feats of strength. "Stripped to the waist," Sandow strutted through the audience "demonstrat[ing] by different movements how great was his command over various muscles." After striking a variety of bodybuilding poses to showcase individual muscles, Sandow enthralled his audience by contracting his biceps and causing them to "rise and fall in time with music." Then, applying the technique he regularly used in his act, "Sandow placed the hands of some of the bystanders to the skin over [his] chest walls and other parts of the trunk of [his] body, with the result that a young fellow described the sensation of being like that of 'moving your hand over corrugated iron." Under the auspices of Lt. Colonel G. M. Fox, who brought Sandow to Woolrich, the bodybuilder visited other military posts, giving similar demonstrations of his muscles that looked "like snakes coiling and uncoiling themselves under his skin."42

Sandow's musculature also came under medical scrutiny on a trip to San Francisco, California where Sandow's manager Florenz Ziegfeld arranged for a "private reception for one hundred of the city's prominent physicians and members of the press." Sandow continued his hands-on display, allowing members of the audience 
feel his biceps that were reportedly as "firm as wire cables." 43 Ziegfeld had done the same in Chicago where he challenged the city's medical community to find a single flaw in the bodybuilder's physique and widely publicized the doctors' inability to find even one. $^{44}$

Sandow's Magazine also played to the medico-bodybuilding connection for legitimacy. When still titled Physical Culture, the Sandow publication advertised that in reference to articles "dealing with the theory and practice of Physical Culture... its scientific side will not be ignored... ." Sandow also boasted the periodical would include "[a]rticles by leading Medical Specialists and Scientists treating of Physical Culture from their special standpoints." 45

The crowning moment in Sandow's career as medicobodybuilder took place in 1911 when he was appointed "Professor of Scientific and Physical Culture," to King George V. While the office was largely honorary, the king actually used Sandow developers and had visited Sandow's Institute of Physical Culture. This position secured Sandow official ranking as what might be termed a "scien-tistic," if not scientific, icon.

\section{"Doctor" Sandow's Physic of Physical Culture}

In an age wracked by fears of depletion, a brawny, larger than life, Sandowesque body was seen as the perfect antidote for neurasthenia. While George Beard had originally written against bodybuilding-type cures for neurasthenia, because "the nervous weaken themselves by trying to make themselves strong by dumbbells, [and] Indian clubs... , later works, such as Watson Savage's "Exercise in the Treatment of Neurasthenia," in the Journal of Advanced Therapeutics (1909), John Bowler's "The Hygienic and Physical Exercise Treatment of Cardiac and Neurasthenic Cases," in the New Albany Medical Herald (1910) and Bernard Talmey's Neurasthenia sexualis: A Treatise on Sexual mpotence in Men and 
in Women (1912) all heralded exercise as a cure for neurasthenia. Francis Gosling, in his text Before Fretd: Neurasthenia and the American Medical Community, 1870-1910, states that while not all physicians advocated exercise as the cure, at the very least, "most... used exercise as an adjunct to other treatments... ."

By 1918, Sandow had been writing about neurasthenia for some time without ever directly addressing the malady. That year, however, marked a change. In Life is Movement, Sandow analyzed neurasthenia as systematically as any doctor, including Beard himself, had done. ${ }^{47}$ For the "Professor of Scientific and Physical Culture," this was a chance to flex his intellectual muscles. Now, later in his life, with the credentials of a career as the first man of bodybuilding, possessing international fame and a newly acquired "professorship" in hand, Life is Movement was a chance at serious scientific scholarship for the aging muscleman. For the premier muscular Christian, the duty ahead was clear, namely: "The Physical Reconstruction and Regeneration of the People (A Diseaseless World)."

In Life is Movement, Sandow tackles the affliction head-on and attempts to carve out his own niche in the medical literature, writing:

No other book on this subject that I have seen has probed to the root cause of this condition, and no other author, medical or otherwise, has seemed to realize that it is entirely the result of a diminished and diminishing nervous income with an increased and increasing expenditure, and that to obtain a balance between them, and still better, to increase income far beyond expenditure, is the only way to overcome this condition permanently. ${ }^{48}$

Sandow distinguished between his own methods and those of Beard, which he suggested were "inclined to alarm the victim of

+6. Gosling. p. 121.

47 Iffe is Movement originated from an eartier Sandow texl. The Construction and Reconsuruction of the Hownan

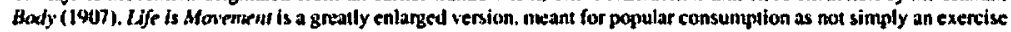
manual- boul a holistic life enhancement icst.

48 Sandow. Life is Mor rmem (l ondon: National Iteahh Press, c. 1918), p. 405. 
[neurasthenia], or, at least, to aggravate the fear ever present, and especially in people who have not been educated from childhood in the langunge of anatomy, physiology and pathology, or, indeed, in scarcely anything attaching to the human form, shape, substance, organization, and the manifold operations ever going on in the human body." 49

Sandow emphasized his medical credentials as a "Professor of Scientific and Physical Culture" with references to "anatomy, physiology, et al." and the "field of therapeutics", which he claimed to have made "peculiarly [his] own after nearly 30 years of personal study, observation and experience."so No-longer "only" a bodybuilder, the legitimized "professor" could now set his own practical, non-threatening, "scientistic," skills to tackling the great medical dilemma of his age. The man whose body had represented the antithesis of neurasthenia would now offer a prescription for the long suffering male.

Despite the fact that he attempted to differentiate himself from prior medical literature dealing with nervousness and from George Beard in particular, Sandow's treatment of the malady was strikingly similar to the standard prescriptions of the era. Although his list was shorter than Beard's improbably long inventory, Sandow presented some 150 traits by which to recognize nervousness, which he considered less a disease than "a morbid condition ... most favorable to other diseases." This echoed George Beard who wrote that neurasthenia "...together with all the symptoms of diseases that evolved from it... is to be distinguished... from organic disease." For both men neurasthenia was something greater than a simple ailment: it was an overarching malady.

In chronicling this "morbid condition," Sandow frequently drew upon the "depletion" fears, economic metaphors, and Veblenesque criticisms of wastefulness prevalent during the era. $\mathrm{He}$ favoured the language of biological economics, including phrases 
such as: "diminishing nervous income," "health-capital," "business of life," and "wealth of health." He used the analogy of the body as a business, a corporation which needed to balance "income and expenditure... avoid[ing]... any infringement on capital or reserve... to safeguard the firm in every way against insolvency and bankruptcy." He called upon the doctor to be a "health accountant," practicing preventive medicine instead of waiting to aid the patient once disease had occurred. He insisted that individuals themselves needed to be vigilant captains of industry: "Just as the soundest and oldest of business houses can be brought to disaster by mismanagement, so the strongest and healthiest body may succumb to neurasthenia by misconduct or mis-direction of affairs, or for want of close supervision over income and outgo... ." The bodybuilder continued: "Neurasthenia is of all health troubles the one most selfincurred.... It is brought about, in the first place, through one's own mismanagement of one's vital affairs, mainly through lack of knowledge and experience, and for want of a proper system of what I may call health-accountancy."

There are many parallels between Sandow's and Beard's approaches to neurasthenia. Sandow described the disease as "the result of spending nervous energy faster than it can be made, or replenished." Beard asserted that "[n]ervousness is strictly deficiency or lack of nerve force." Beard saw nervousness as the result of "modern civilization..." and "the great mental activity... brain-workers." Sandow's saw harm in modernity and viewed the "brain worker... [as] naturally the most predisposed to neurasthenia."5I However in Life is Movement, which was published some thirty-seven years after American Nervousness, Sandow sought to fundamentally alter the conceptualization of neurasthenia to incorporate emerging theories of traumatic neuroses expounded by Hermann Oppenheim and Herbert Page, Freudian notions of war neurosis, and modern concepts of "shock."52 
Sandow linked the war-exacerbated neurasthenia to that of the sedentary "stockbroker" or the "student burning at once the midnight oil and his own life force." He heroicized the neurasthenic brain-worker by equating him with the soldier, suffering from "shellshoc[k]", "amid the frenzy of war and dazed by the roar of guns, [who] loses all control over himself and is drained quickly of his nervous force." Nervousness, while self-induced, was not entirely shameful so long as efforts were made at self-cure. The curative methods that Sandow, and other contemporaries, advocated were in some ways different from those espoused by Beard. Gone were electrical/galvanic current therapies and bromides of Beard's generation. Instead, Sandow, in keeping with the holistic theme of Life is Movement, espoused a "natural" cure which was "partly physical and physiological and partly psychical.".53

Sandow set guidelines for proper diet, rest, exercise and mental outlook. He cautioned that "physical exercise, like medicine, may be a valuable friend or a dangerous enemy" and admonished, like Beard. that rigorous exercise "may simply add to the sufferer's expenditure of nervous energy... at a time when new energy should be being placed to his credit." Sandow warned that, "fast and jerky muscular movements [which] increase strain upon the heart and tend to exhaust nervous vitality instend of strengthening it.".54 Instead, he advocated lighter exercises that emphasized quality over quantity. Sandow stressed slow, steady movements where one concentrated on feeling the muscular contraction "with the maximum physical and mental effort."5.5 The Sandow system combined this systematized exercise with a nutritious diet, plenty of "meditative" rest, and positive affirmations.

While Sandow had long fashioned his biography to portray himself as a nervous, "delicate" youth who had conquered neurasthenia, Life is Movement, marked the introduction of the neurasthenic Sandow, who, like Theodore Roosevelt, was forced to win his manhood more than once. 56 "Strong and robust as I was not

52 Wolfgang Schivelbusch, The Roilway Joumry: The Indworialisation of Time and Space (Rerkeley: Univensity of California Press, 1986 [| 1977]|. pp. 144-148.

53 Sandow. Life is Mfovemen. p. 423.

54 Sandow, Life is Mowement. pp. 415. 429.

s5 loid. p. 429. 
so very many years ago, and in the prime of my vigor," Sandow related, "I was impelled, under the driving spirit of my great enthusiasm in the very cause I am now advocating, to spend nervous energy faster- much faster- than I could make it, although I lived a stern and disciplined life...." In an effort to create a system to cure others, he fell victim to a "nervous breakdown." Sandow was fortunate to be "in good physical condition... with undoubted advantages over the average man...," yet for all his muscularity and although he now claimed to have "never had a day's illness or suffered from any disease in [his] life," Sandow still suffered a "nervous collapse." muscles "seemed almost to fade away." "Despaired of," yet again, Sandow took to following his own prescriptions for conquering neurasthenia and cured himself, just as he had done as a "delicate" youth. "Indeed those who see me today at 52 , as fit as, if not better than, l ever was in my life and again turning the scale at about 15st., can scarcely [believe] this."

After submitting himself to a systematic muscle-building and life-enhancement program, cured and re-cured, filled with practical knowledge and the "muscle" to back it up, "Dr." Sandow had saved his masculinity and returned to the condition of his "youthful prime."58 Sandow concluded "How I, Myself, Broke Down," by writing, "I transformed myself in earlier life from a delicate youth into a strong and healthy young man, and I mention this incident for the encouragement of others and to give them the assurance that I have a sympathetic understanding of similar cases." 59

To the men of the nervous age, what could be more masculine than a bodybuilder's muscular physique and the psychological power it could bring to bear? If ever there was a way to combat debilitated manhood, this was it. Had not Sandow himself been "despaired of" and "exceedingly delicate?" The way, therefore,

\footnotetext{
S6 This theme of repeated breakdown was a comanon one, says I: Arthony Rotundo. "Alhowgh some inen suffered only one bout of neursuthenia, it was comnon to have recocuming breakdowns. Even when symptoms ebted. the men plagued by this illiness watched anxiously for signs of its retum ." p. 186

57 One woaders how a boy whose life was "more than once... despaired of." coubd lave never suflered a day of illness prior to his "breakidown."

S8 Sandow. Uff is Mourinent. pp. \$20-421.

59 It should be noted that at age fify. wo, Sanibow was neither 154. nor in prime condition. Sandow. Life is Mourmont. p. 421 .
} 
to win back manhood was assuredly through the methods Sandow had used. If he could go from weakling to he-man, ${ }^{60}$ so could others. Thus was (and still is) the promise of bodybuilding.

Sandow's own situation explicitly illustrates the implicit promise of bodybuilding and regeneration. Sandow, in words and much more so in image, promised a cure for neurasthenics who "before beginning my system of physical training have been so weak that their doctors have thought little of the prospect of saving their lives." Using the Sandow system, however, like the Prussian bodybuilder himself, they too could become the strongest of men.61 "Dr." Sandow's prescriptions for recreating men through muscle typify the tenor of the times and the themes which ran through the "man-making" endeavor of bodybuilding. The theme of near limitless improvement, growing in strength since the dawn of the Enlightenment, was the promise of the Gilded Age. Industrial machines could be continuously improved, why not men too?

In his text, Bodies and Machines, Mark Selzter writes of "coordination of bodies and standards in the rise of eugenics and euthenetics," during the nineteenth century and makes reference to Sandow's Body-Building or Man in the Making and The Construction and Reconstruction of the Human Body as one evidence of this theme of human improvement. Intriguingly, Sandow spoke to human improvement not only through his bojoks, but also through his name. Bodybuilding historian David Webster relates that Sandow and his manager Professor Atilla, devised the stage name Eugen from the word eugenics. Sandow's Magazine frequently ran articles and printed editorials dealing with eugenics, often written by prominent eugenicists such as Francis Hutchinson, and claimed to specialize in articles relating "physical culture... with respect to the evolution of the human race." 62

Eugenics, however, seems to betray the self-improvement ethos of bodybuilding by implying that, despite what "Dr." Sandow might prescribe, better breeding was the ultimate avenue to salvation.

60 To paraphrase later muscle-bailuting guru Chaskes Allas. 61 Sandow, Sirmgth. p. I4.

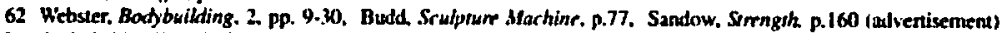
[not included in all copies]. 
There are also troubling consequences for the ever-changing myth of the delicate Muller and the perfected Sandow. The premier muscular Christian eventually reconciled the seemingly contradictory nature/nurture bodybuilding divide by stating that the Sandow system was one of "higher Eugenics that will inevitably lead to a "healthy more vigorous humanity." 63 Eugen's eugenics, then, was a system of muscular predestination. The saved, already genetically superior, recognized himself as such and, consequently, built his musculature to evidence his redemption. Amidst the contradictory currents swirling about bodybuilding, Sandow's non-eugenic eugenics was another feature that was not to be rationalized but simply accepted on faith.

\section{Sandow the Modern Prometheus: Bodybuilding as Recreation and "re-Creation"}

Today the catch-all disease of neurasthenia has been replaced by numerous specific psychoses and neuroses. Bodybuilding, the medico-scientific means of bodily reconfiguration, has split into a marginalized professional pseudo-sport and a common activity taking place in numerous gyms and "fitness centers." Eugen Sandow, once one of the most popular men in the world, lies in an unmarked grave in England. His legacy has been largely reduced to a cursory note in texts dealing with Ziegfeld or nineteenth century sport, with occasional mention in a small body of literature produced by scholars of the "iron game."

Born of recreation and the promise of re-creation, the technological "labor of leisure" that emerged during the gilded age allows us to view the nineteenth century through yet another lens: that of the body built. While bodybuilding may not be the first image that comes to mind when one ponders the Victorian and Edwardian eras, Sandow's personal impact and interaction with luminaries such as Theodore Roosevelt, Sir Arthur Conan Doyle, Thomas Edison, and Kaiser Wilhelm II, among others, attests to the importance of both the man and his technology for the times. Bought and sold as a scientific antidote to a technologically created disease, bodybuilding proved unable to cure neurasthenia, but the ideal of Superman was common 
in the literature of the period. Nietzsche, who spent his later years engaged in medical research, claimed neurasthenia was a "denial of the body and a glorification of powerlessness." 64 Surely bodybuilding was the antithesis of this: an affirmation of the body and a glorification of muscular power. Yet, the fact that Sandow, the premier bodybuilder, attested to having suffered a nervous relapse was the grimmest evidence that the bodybuilding cure was no panacea for the modern age. If the "blond god" could not defeat nervousness, who could? Like Nietzsche, George Bernard Shaw glorified the superior man, celebrating Prometheus as "the first specimen of the ... Superman in history." the fire of the gods to make humanity superior to other animals, was the perfect model for Sandow the man-maker. Yet Sandow proved unable to provide for men in the manner of Prometheus.

Sandow may be best understood in the terms of Mary Shelley's nineteenth century masterpiece, The Modern Prometheus. Where Victor Frankenstein attempted to fashion a man through component parts and an electric spark (the favorite neurasthenia cure in George Beard's early works), Sandow endeavored to create manhood through the science of muscle building. Both were self-styled, European-born medical men. Like Sandow, who suffered a nervous collapse in the midst of his man-making endeavors, Victor Frankenstein "became nervous to almost a painful degree... his voice became broken, [his hands] trembl[ed; and he] became as timid as a lovesick girl" while building his body. Like "Dr." Sandow, Dr. Frankenstein "believed that exercise... would soon drive away such symptoms." 66

Both Sandow and Frankenstein set out to reconstruct men, with mixed results. Frankenstein was not content to create a man of "normal" proportions, instead sought to create a superman, a "being of gigantic stature," the original body-built. Frankenstein worked with "bodies deprived of life, [which once had been] the seat beauty and strength." just as Sandow attempted to reinvigorate lifeless

64 14hiz. p. 23.

65 Arthur Ncthercot. Men and Supennen (New York: Jknjamin I1toom. 1966 [1954]h p. 266.

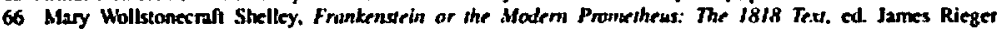
(Chicago: University of Chicago Press. 1982 [1974]. p. 51. 
neurasthenic bodies with, as he put it, "physical strength and beauty. 67 "Tragically, Frankenstein found that even a systematized scientific assemblage of body parts would not make a man. Frankenstein, like Sandow, sought a powerful-looking ideal. The description of his creation ("his limbs were in proportion, and... his features [were] benutiful. Beautiful!- Great God! His... skin scarcely covered the work of muscles and arteries beneath...") could easily been the quote of a nineteenth century doctor commenting on the physique of Eugen Sandow. ${ }^{68}$ Despite the movie-induced popular image of Frankenstein's creation as a hideous creature, it is important to note this was not Mary Shelley's image of the "monster." In fact, the 1831 cover plate of Frankenstein or The Modern Prometheus, depicts a muscular, highly defined, built-body to rival the physique of any bodybuilder of the nineteenth century, including that of Sandow. 69

While Shelly's Frankenstein played no role in the development of bodybuilding, it is important to the understanding of the body built. Reconfiguring manhood through science was the goal of Victor Frankenstein, just as it was the goal of Eugen Sandow and the host of bodybuilding enthusiasts who proliferated throughout the age of nervousness. Manufactured masculinity could be achieved in fiction through building bodies and, supposedly, in reality through bodybuilding. Yet, bodybuilding as man-making was a fiction all its own.

Man-making through the technology of bodybuilding was imagined as a means of reconfiguring masculinity through scientific methods. Bodybuilding ultimately failed to provide a concrete masculinity but this should not diminish its importance to the age and should not diminish our conceptualization of man-making either. Throughout the twentieth century, bodybuilding icons including Charles Atlas, John Grimek, Steve Reeves and Arnold Schwarzenegger continued the Iradition begun by the Sandow-

67 Sandow, Sirngth, p. 159 (Advertiscument) [nol all copies have this odvertisement].

68 Shelley. pp. 47, 49. 52.

69 Anne K. Mellor, Mary Shelley: Her Life. Her Fiction, Her Monsters (New York: Methuen. 19881, p. if. 
generation of bodybuilders and provided a vision, if flawed, elusive and, to many, illusory, of masculinity that endures to this day. ${ }^{70}$

At the beginning of the twenty-first century, with the proliferation of health clubs and fitness centres, the fetishized images of musclemen and the requirement that the action movie star be "well-built", both popular and scholarly discourse have taken up the task of interpreting bodybuilding and the many themes which accompany it. As other disciplines explore the meaning of physique enhancement through muscle building, it is important that historians continue to investigate the history of the body and the social construction of masculinity. The history of bodybuilding provides an excellent vehicle to examine the plethora of social, cultural, economic and religious aspects of the stereotypical masculine body and mind. Understanding and analyzing bodybuilding as a technology of physical transformation holds a great many possibilities for reconceptualizing the body as a built environment and offers new avenues for historians of technology, as well as those of public health and medicine, to reexamine the construction of the human body. It is hoped that this paper will act as a springboard towards that end.

70 For more on Chartes Allas see, Nicholas Turse, "Charles Atlas," St. James Encyclopsedia of Populor Culturr, eds.

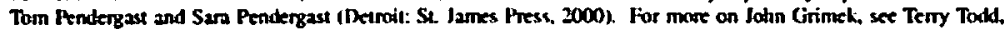
"John (irimel - The Man," Iron Gane Whstony vol. 5, no. 4/wol. 6, mo. I (double issucl (April 1999), 1.5 and David

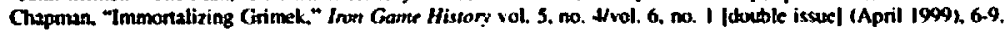
for more on Steve Reeves, sec Jan Todal and Teny Toxk. "The I ast Interview." Imn Gane Hintory vol. 6, no. 4 (1Decemher 2000), 1-14 and Nictolas Turse. "Steve Reeves." St. Janws Encorlopedia of Popular Culture, eds. Tom Pendergast and Sara Pendergast (Detroil: St. James I'ress. 2000). 